\title{
Deafferentation of the vestibular organ: Effects on atropine-resistant EEG in rats
}

\author{
SHAI SHOHAM and YU-CHIEN CHEN \\ University of Illinois, Champaign, Illinois \\ TERRY L. DEVIETTI \\ Central Washington University, Ellensburg, Washington \\ and \\ PHILIP TEITELBAUM \\ University of Illinois, Champaign, Illinois
}

\begin{abstract}
Cortical and hippocampal EEG patterns that persist after atropine sulfate administration are defined as atropine-resistant. In the rat, such patterns are movement-related, cortical low-voltage fast activity (LVFA) and movement-related, hippocampal rhythmic slow activity (RSA or "theta"). A close relationship exists between head movement and activation of atropine-resistant EEG. In the present study, we asked whether manipulation of vestibular sensory input would affect atropine-resistant EEG. To allow experimenter control, 6 vestibular-intact rats were made cataleptic with haloperidol and were then injected with atropine sulfate. Movement of the rats' heads by the experimenter (passive head movement) failed to activate atropine-resistant EEG. These animals were then rotated on a turntable. Such vestibular stimulation, the effectiveness of which was reflected by postrotatory ocular nystagmus, also failed to activate atropine-resistant EEG. These and 5 other rats were then subjected to surgical or chemical deafferentation of the labyrinth. They were tested for EEG atropine resistance before and after this surgery. Although atropineresistant EEG patterns in response to active bodily movements still appeared after vestibular deafferentation, the frequency of hippocampal RSA during active movement was reduced with or without atropine. In contrast, an atropine-sensitive component in the hippocampal EEG during immobility was not changed by vestibular deafferentation. We conclude that vestibular reafferent feedback is neither necessary nor sufficient for the atropine-resistant EEG, but that such feedback from active movement has a modulatory effect on hippocampal RSA.
\end{abstract}

The effect on the EEG of atropine sulfate, a drug that blocks muscarinic acetylcholine receptors, allows one to dissect the motor behavioral repertoire of the rat into two major categories. One category corresponds to atropinesensitive and the other to atropine-resistant EEG (Vanderwolf, 1975).

The neocortical EEG in the nonatropinized rat during the wakeful behavioral repertoire as well as during REM sleep consists largely of low voltage and fast activity (LVFA; $<100 \mu \mathrm{V},>15 \mathrm{~Hz}$ ). The neocortical EEG of the atropinized rat during immobility, either when awake or during tonic REM sleep, shows high-voltage slow waves (HVSA; $>100 \mu \mathrm{V},<4 \mathrm{~Hz}$ ). A similar but less

This work was supported in part by National Institutes of Health Grant R01 NS11671 to P. Teitelbaum and by National Institutes of Health Senior Research Fellowship 1 F33 NS07383 to T. L. DeVietti. It was conducted while T. L. DeVietti was on professional leave at the University of Illinois. S. Shoham's present address is The Jerusalem Mental Health Center, Givat Shaul, P.O. Box 140, Jerusalem 91001, Israel. Y.-C. Chen's present address is 375 Best Drive, Apt. A, Athens, GA 30606. P. Teitelbaum's present address is The University of Florida, Department of Psychology, Gainesville, FL 32611. Correspondence may be addressed to T. L. DeVietti, Psychology Department, Central Washington University, Ellensburg, WA 98926. dramatic change from LVFA to HVSA appears in the atropinized rat during motor acts such as grooming, chewing, tooth chattering, and licking. But during locomotion, running, jumping, turning, swimming, and phasic REM sleep, LVFA is present in the atropinized rat-this is the neocortical atropine-resistant EEG.

The hippocampal EEG rhythmic slow activity (RSA; $300-1500 \mu \mathrm{V}, 7-12 \mathrm{~Hz}$ ), or "theta," also displays an atropine sensitivity/resistance correspondence with motor behavior. In the nonatropinized rat, immobility, grooming, chewing, licking, and tooth chattering are accompanied by hippocampal large irregular activity (LIA; $500-1500 \mu \mathrm{V}$ ). In contrast, hippocampal RSA is observed just before making an escape jump in a learned avoidance task and during locomotion, jumping, running, turning, swimming, and REM sleep. In the atropinized rat, LIA remains during immobility, grooming, and so forth, and also replaces the RSA of immobility just before making an escape jump or during tonic REM sleep (Robinson, Kramis, \& Vanderwolf, 1977; Vanderwolf, 1975). During locomotion, running, jumping, and so forth, and during phasic REM sleep, hippocampal RSA is presentthis is the hippocampal atropine-resistant EEG. 
Further observations have revealed a close temporal association between head movements and the appearance of the atropine-resistant EEG in the neocortex and hippocampus (Schallert, DeRyck, \& Teitelbaum, 1980; Vanderwolf, 1975). Movement of the head is a component of many motor acts in the rat's behavioral repertoire and induces strong signals from the vestibular apparatus of the inner ear (Gacek, 1975). Perhaps these vestibular signals participate in the neural mechanism of the atropineresistant EEG. A unique potency of vestibular stimulation for the modulation of hippocampal EEG was noted by Winson (1976), who found that horizontal rotation of a curarized (nonatropinized) rat on a turntable induced hippocampal RSA, whereas stimulation in other sensory modalities failed to induce hippocampal RSA. Furthermore, in the nonatropinized rabbit, Whishaw (1982) noted an acceleration of hippocampal RSA frequency during the righting response. In light of these findings, we were interested in the question of whether manipulation of the vestibular system would affect atropine-resistant EEG.

In an early investigation of this question, Vanderwolf (1975) injected rats with both phenothiazine (to reduce self-initiated movement) and atropine sulfate. He reported that movement of the rat's head by the experimenter (passive head movement) did not induce atropine-resistant EEG even though the vestibular apparatus was presumably stimulated.

In the present investigation, we made similar observations and added other tests of vestibular stimulation. We also conclude that vestibular stimulation alone does not activate atropine-resistant EEG. We then denervated the vestibular sensory apparatus either surgically or chemically and found the atropine-resistant neocortical EEG intact and the hippocampal atropine-resistant EEG, though clearly present, somewhat reduced. Moreover, the predominant LIA frequency during immobility was reduced from $6-7 \mathrm{~Hz}$ to $3-4 \mathrm{~Hz}$ with atropine both before and after labyrinth deafferentation. In addition, hippocampal RSA frequency during active movement was reduced by about $0.60-1.0 \mathrm{~Hz}$ following labyrinthectomy both before and after atropine.

Since removal of vestibular signals did not affect the frequency of the hippocampal LIA during immobility or during passive movement, these results suggest to us that reafferent vestibular signals from self-initiated movement increase the frequency of hippocampal RSA.

\section{METHOD}

Twenty-one male Long Evans hooded rats (University of Illinois Psychology Department colonies) weighing 230-400 g were implanted with electrodes for bilateral neocortical and hippocampal EEG recording as previously described (DeRyck \& Teitelbaum, 1978; Schallert et al., 1980). In brief, the electrodes were bipolar with one lead of the formvar-coated, $250 \mu \mathrm{m}$, stainless steel wire 1.0-1.2 mm longer than the other. The implantation coordinates were: cortex A3.5, L2.0, V2.0 mm; hippocampus: P3.5, L2.5, V3.5 $\mathrm{mm}$ with the head level between bregma and lambda. The bregma served as the A-P reference, and the skull surface served as the vertical reference. Of the 21 implanted animals, 10 did not complete the experiment for a variety of reasons, including poor, incomplete, or movement-artifact contaminated EEG recordings $(n=7)$, or death during labyrinthectomy $(n=2)$. In addition, 1 animal developed a tumor and was sacrificed.

Two methods of vestibular deafferentation were used: surgical (physical removal of vestibular afferents) and chemical (injection of a toxin known to destroy labyrinth cells).

\section{Surgical Deafferentation $(n=3)$}

Under Ketamine + Acepromazine anesthesia (mixture of 100:1, respectively, injected i.m. or i.p., $1.0 \mathrm{ml} / \mathrm{kg}$ ), a rat was positioned ventral side up. A ventral approach to the labyrinth was taken to avoid uncontrolled damage to Scarpa's ganglion (Cummings, 1924; Greene, 1963). The bulla was exposed by blunt dissection and was opened with a drill. The pterygopalatine artery was used as a landmark and was not ligated (Cummings, 1924; Greene, 1963). Posterior to the cavity occupied by the tensor tympani, the cochlea was opened with the dental drill. The excavation was continued by alternately drilling, aspirating, and drying with small pieces of absorbent paper until the bony cavity of the utricle and saccule was clearly exposed. This was used as a visual criterion for complete removal of the fibers innervating the labyrinth. Because of the ventral approach, the auditory cochlea was destroyed in the drilling process in all animals. Following surgery, the rats were injected $\mathrm{i} . \mathrm{m}$. with sterile penicillin (Dual-Pen, Med-Tech Inc., Elwood, KS), $0.2 \mathrm{ml}$ into one leg muscle once a day for 3 days.

\section{Chemical Deafferentation $(n=8)$}

Following Horn, DeWitt, and Nielson (1981), the rats were anesthetized with equithesin $(0.35 \mathrm{ml} / 100 \mathrm{~g})$, and $0.10 \mathrm{ml}$ of sodium arsanilate solution (100 mg/ml in saline) was injected into each middle-ear cavity. Under a dissection microscope, the needle was inserted through the tympanic membrane until resistance by the auditory ossicles was encountered. The solution was infused uniformly within 3 to $5 \mathrm{sec}$. Then, each ear canal was tightly packed with gelfoam and the animal was put back in its cage to recover. In some cases, the solution appeared to pass into the eustachian tube, as was evident from liquid flowing from the nostrils. In such cases, the animal was immediately aspirated. Occasionally, chemical deafferentation had to be repeated to obtain complete loss of vestibular function (righting ability, etc.).

\section{Experimental Procedures}

Experimental procedures were carried out during the dark phase of a 12-h light-dark cycle.

\section{Tests for Labyrinth Function}

Following a 7-day recovery period from EEG-electrode implantation, the rats were first tested for intact vestibular function. These tests were repeated throughout the different phases of the experiment. One test was the ability of the rat to right itself in the air when held supine and then released about $30 \mathrm{~cm}$ above a foamrubber cushion. $A$ normal rat rights itself in the air while falling and lands on all four feet. A labyrinthectomized rat does not right itself and lands on its side or back. A second test was contact-righting on the ground. When placed with its back in contact with the ground, the labyrinthectomized rat rights itself as does the normal animal. However, if animals are provided pressure contact with the feet by placing a Plexiglas board on the ventral surface of the animal's feet while it lies supine with its back in contact with the ground, a clear differentiation between normal and labyrinthectomized animals appears. The normal animal continues to right itself, whereas the labyrinthectomized animal does not. Labyrinthec- 


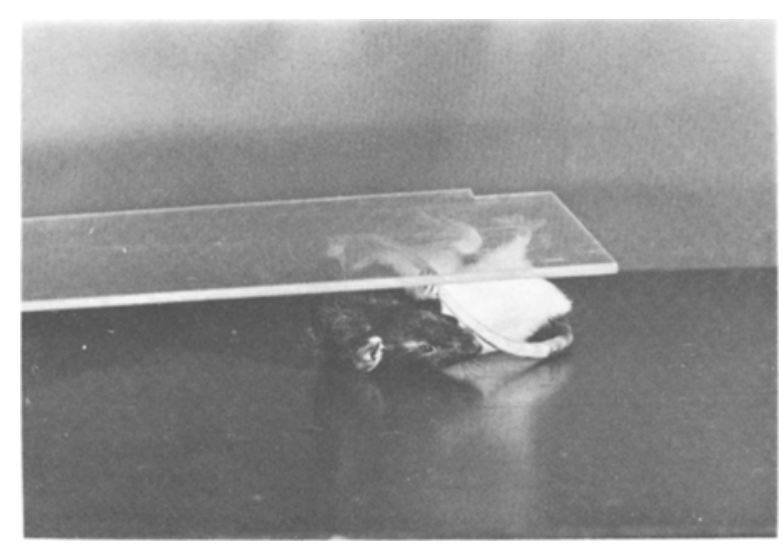

Figure 1. Inhibition of contact-righting by foot contact in the labyrinthectomized rat.

tomized animals step with respect to the board as they would with respect to "real" ground as shown in Figure 1.

\section{Tests for Atropine-Sensitive and}

\section{Atropine-Resistant EEG}

All phases of the testing procedures were videotaped. A splitscreen technique allowed a simultaneous display of the EEG and behavior. These tapes allowed us to correlate the EEG more accurately with the movements of the animals.

Following the tests for labyrinthine function, the animals were individually placed in a large enclosure and the EEG was recorded (DeRyck \& Teitelbaum, 1978). A multiconductor shielded cable linked a connector on the rat's head to a nine-channel mercury commutator, which in turn was connected to $\mathrm{AC}$ preamplifiers (P5 and 7P511) of a Model 7 Grass polygraph. The bandwidth (3 dB cutoff points) for neocortical EEG was 1-35 $\mathrm{Hz}$ and 1-30 Hz for hippocampal EEG. If the recordings from the two cortical electrodes showed LVFA, the two hippocampal electrodes showed appropriate LIA and RSA, and none of the leads showed movement artifact, the animals were tested to determine the effect of atropine sulfate ( $50 \mathrm{mg} / \mathrm{kg}$, i.p., administered $1 \mathrm{ml} / \mathrm{kg}$ ) on the EEG. Thirty to $45 \mathrm{~min}$ following injection, tests were conducted in which we recorded the EEG while the animal was in the enclosure. The duration of these tests was variable (10-20 min), but included EEG recordings during movement and immobility. All atropinized animals showed clear differentiation of cortical HVSA $(0.5-4.0 \mathrm{~Hz}$, $0.3 \mathrm{mV}$ or greater) from cortical LVFA and hippocampal LIA from RSA (4.0-12.0 Hz, $0.5 \mathrm{mV}$ or greater).

The main frequency of hippocampal EEG was manually analyzed. Four-second episodes of transition from LIA to RSA were chosen, in which the first $2 \mathrm{sec}$ were LIA and the next $2 \mathrm{sec}$ were RSA. Waves crossing the EEG zero-voltage line were counted. A run of fast wave modulations of LIA $(>12 \mathrm{~Hz})$, small in amplitude $(<30 \mu \mathrm{V})$ and undulating around the zero-voltage line was counted as one zero-crossing. At least six episodes were sampled from each of the four conditions (i.e., pre- versus postlabyrinth deafferentation and nondrugged versus haloperidol plus atropine treated).

\section{Tests for Sufficiency of Vestibular Activity}

\section{to Mediate Atropine-Resistant EEG}

Active and passive head movements. We produced catalepsy in 6 of the vestibular-intact rats by giving them haloperidol $(5.0 \mathrm{mg} / \mathrm{kg}$ i.p.), and then administered atropine $15-20 \mathrm{~min}$ later. It is known that haloperidol does not disrupt atropine-resistant EEG (DeRyck \& Teitelbaum, 1979), and we also observed this result. Cataleptic rats display little or no self-initiated movement but their vestibular function is intact, as is evident from their ability to right themselves in the air. By tailpinch, they can be induced to make a single-phasic active head movement. To assess the effects of passive head movement, one of the experimenters moved the rat's head gently vertically or horizontally. Without knowledge of the EEG, the experimenter activated a marker on the EEG printout when no resistance from the rat was felt during the induced head movement.

Vestibular stimulation in the absence of head movements. To assess the effect of vestibular signals on the EEG of atropinized vestibular-intact rats in the absence of head movements, the cataleptic atropinized rats were placed on a turntable (Lazy Susan), which was turned by hand. The rate of rotation was relatively constant, with 10-15 rotations occurring within 15-20 sec. Postrotatory ocular nystagmus (repetitive horizontal eye movements stimulated by the persistent aftereffects of fluid motion in the vestibular apparatus; Jongkees, 1975) appeared following the cessation of the rotation. The onset, duration, and offset of the nystagmus was marked on the EEG printout by a remote event-marker. In contrast to normal rats, cataleptic rats do not display head nystagmus simultaneously with ocular nystagmus. In effect, vestibular stimulation was achieved in the absence of head movement, thus isolating the contribution of vestibular stimulation from the act of head movement as a whole. A comparison of ocular nystagmus to head nystagmus in noncataleptic rats would be of interest here. However, due to technical difficulties involved in forcing rotation on noncataleptic rats while they are connected by an EEG cable, we did not include this comparison. In another test, the experimenter lifted the horizontal turntable with the cataleptic rat on it and moved it gently up and down. The purpose was to stimulate the gravity receptors of the labyrinth (Gacek, 1975) in the absence of head movements. Finally, the experimenter gently tilted the turntable to the rat's right or left. To compensate for the pull of gravity, the cataleptic rat "braces"; that is, it adjusts its posture by extending the limbs on the lower side and flexing the limbs on the higher side. Typically, this postural adjustment is made with little or no head movement.

\section{Tests for the Necessity of Vestibular Activity \\ to Mediate Atropine-Resistant EEG}

Following this phase of the experiment, we subjected all 11 rats to vestibular deafferentation. Three to 4 days later, the tests of vestibular function were repeated. If vestibular responses were absent, the tests described above were repeated along with EEG recordings.

\section{RESULTS AND DISCUSSION}

The purpose of this experiment was to evaluate the role of vestibular feedback from head movement in the atropine-resistant EEG. We were interested in sampling only clear examples of transition from immobility to head movement. Therefore, we selected portions of the EEG record when, by visual judgment from the videotape, the animal had been immobile for at least 1 sec followed by at least $1 \mathrm{sec}$ of head movements. An additional criterion for "immobility" was that hippocampal LIA was present. The effect on the EEG of movements of the head alone or of movements of the animal which included head movement and which lasted at least $1 \mathrm{sec}$ was then evaluated. Movement sequences associated largely with atropinesensitive EEG (grooming, chewing, licking) were not included in the analysis. In these sequences, short pauses in head movement make it difficult to resolve immobility from movement.

The experimental manipulations produced consistent qualitative changes in the EEG in each of several tests with all 11 animals. In 4 of these animals, we analyzed 
Table 1

Correlations of Cortical and Hippocampal EEG with Movement

\begin{tabular}{|c|c|c|c|c|}
\hline \multirow[b]{2}{*}{ Animal } & \multicolumn{2}{|c|}{ Prelabyrinthectomy } & \multicolumn{2}{|c|}{ Postlabyrinthectomy } \\
\hline & Predrug & $\begin{array}{l}\text { Haloperidol } \\
+ \text { Atropine }\end{array}$ & Predrug & $\begin{array}{l}\text { Haloperidol } \\
+ \text { Atropine }\end{array}$ \\
\hline \multicolumn{5}{|c|}{ Cortex } \\
\hline & $\mathbf{A}$ & $\mathbf{B}$ & $\mathbf{E}$ & F \\
\hline DS-7* & $0.00(18)$ & $0.89(11)$ & $0.00(6)$ & $1.00(14)$ \\
\hline DS-13 & $0.00(14)$ & $1.00(17)$ & $0.00(7)$ & $1.00(14)$ \\
\hline DS-15 & $0.00(11)$ & $1.00(18)$ & $0.00(12)$ & $1.00(12)$ \\
\hline DS-17 & $0.00(10)$ & $0.97(21)$ & $0.00(15)$ & $0.95(17)$ \\
\hline \multicolumn{5}{|c|}{ Hippocampus } \\
\hline & $\mathrm{C}$ & D & $G$ & $\mathbf{H}$ \\
\hline DS-7* & $0.95(18)$ & $0.83(11)$ & $1.00(6)$ & $0.80(14)$ \\
\hline DS-13 & $1.00(14)$ & $1.00(17)$ & $1.00(7)$ & $0.87(14)$ \\
\hline DS-15 & $1.00(11)$ & $1.00(18)$ & $1.00(12)$ & $0.92(12)$ \\
\hline DS-17 & $1.00(10)$ & $0.75(21)$ & $0.93(15)$ & $0.69(17)$ \\
\hline $\begin{array}{l}\text { te-The fi } \\
\text { absent). In } \\
\text { absivity } \\
\text { at least } 1 \\
\text { of times } \\
\text { opine sulf }\end{array}$ & $\begin{array}{l}y \text { in each cel } \\
\text { : LVFA or } \\
\text { hes, the EEG } \\
\text { head movem } \\
\text { was sample } \\
y \text {. }\end{array}$ & $\begin{array}{l}\text { phi coeffici } \\
\text { Hippocamp } \\
\text { sessed duri } \\
\text { wing immo } \\
\text { ch animal. }\end{array}$ & $\begin{array}{l}\text { nined from a } \\
\text { or LIA) and } \\
\text { t } 1 \text { sec of im } \\
\text { he values in } \\
\text { or details. }\end{array}$ & $\begin{array}{l}\text { matrix combi } \\
\text { novement (pre } \\
\text { ity and again } \\
\text { heses are the } \\
\text { is animal rece }\end{array}$ \\
\hline
\end{tabular}

the videotapes in detail to quantify the relationship between the EEG changes and movement. These data are presented in Table 1 and were derived in the following manner. First, the number of instances during the experimental session in which a given animal showed at least $1 \mathrm{sec}$ of head movement following at least one second of immobility were counted. Then, the type of EEG present during immobility and during the following movement was tallied in a $2 \times 2$ matrix. The phi coefficient of correlation was determined from these data for each animal. Panel A of Table 1 shows the relationship of the cortical EEG to the two movement categories in the 4 animals without drug administration and before labyrinthectomy. Consider animal DS-13. In this session, there were 14 instances of head movement following immobility. In all 14 instances, LVFA was observed during immobility as well as during movement (and, therefore, HVSA was never observed). Thus, the phi coefficient of 0.00 signifies that the cortical EEG in this condition was unrelated to these movement categories. However, the phi coefficient for this animal following haloperidol and atropine (Panel B) shows that the cortical EEG was perfectly related to these movement categories. This result occurred because, in the 17 movement transitions observed in this session, HVSA was present whenever the animal was immobile and LVFA was present whenever it was moving. The hippocampal data were obtained in the same manner except that, of course, the EEG categories were LIA and RSA. In the following account, we refer to the detailed analysis of the 4 animals shown in Table 1 to reinforce the qualitative descriptions of the data obtained from all 11 animals in each of several tests.

Without atropine and before labyrinthectomy, all 11 rats showed cortical LVFA during both head movement and immobility (Table 1, Panel A). They also showed hippo- campal LIA during immobility and RSA during head movement (Table 1, Panel C). Following the administration of atropine or atropine plus haloperidol, the cortical EEG was HVSA (atropine-sensitive) when the animal was immobile, and LVFA (atropine-resistant) when head movement occurred (Table 1, Panel B). Following drug administration, the relationship of hippocampal RSA and head movement, although still substantial (Table 1, Panel D), appeared less consistent (cf. Table 1, Panels C and D). This reduced relationship occurred because, following atropine sulfate, runs of RSA were discontinuous, interrupted by runs of LIA. These interruptions of RSA by LIA runs were previously observed by Schallert et al. (1980) in vestibular-intact atropinized rats. Although movement appears continuous, it is a sequence linked by transition points. These LIA runs appeared to coincide with behavioral transition points in Schallert et al.'s (1980) experiment and in our study even within a short episode of head movement. Using videotape, the resolution of the relationship of EEG to behavior was limited. Therefore, we set a strict criterion: an episode of 1-sec RSA that was interrupted by LIA was counted as LIA. In this way, if labyrinthectomy had any effect in reducing head-movement-related RSA, we were likely to document it.

Examples of the cortical and hippocampal EEG during immobility, and head movement in the vestibular-intact animal, both before and following drug administration, are shown in the top portion of Figure 2 (Records A and $\mathrm{B}$ ).

Vestibular-intact rats, made cataleptic (totally immobile) with haloperidol and treated with atropine, showed no activation of atropine-resistant EEG during postrotatory ocular nystagmus. Figure 3 (Record A) illustrates this finding. The cortical EEG showed mixed LVFA and 


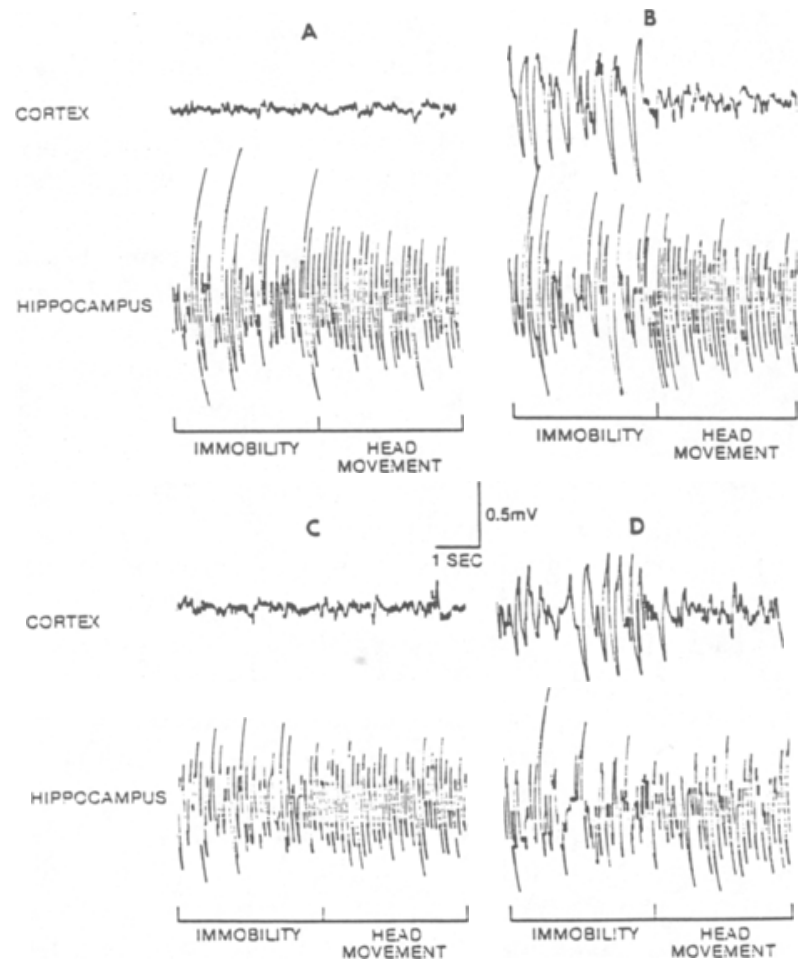

Figure 2. Cortical and hippocampal EEG during immobility and head movements in a representative animal (DS-13). Record $A$, vestibular intact, no drugs; Record B, vestibular intact, atropine and haloperidol; Record C, postlabyrinthectomy, no drugs; Record D, postlabyrinthectomy, atropine and haloperidol. Voltage and time scales, shown in the center of the figure, were identical for all four records. See text for details.

HVSA and the hippocampus showed mixed LIA and RSA as the animais braced against the centrifugal force of the rotation. However, following the cessation of the rotation, and during nystagmus, the cortex showed HVSA and the hippocampus showed LIA. This result was obtained in each of several tests in all 6 animals tested. Since these rats were totally immobile during the period of nystagmus, we conclude that vestibular stimulation, reflected by ocular nystagmus, but isolated from any body or head movement, failed to activate the atropine-resistant EEG. Repeated vertical or horizontal displacement of a vestibularintact cataleptic rat placed on a horizontal (but nonrotating) turntable, as well as passive head movements induced by the experimenter, also failed to activate the atropineresistant EEG. In contrast, active movement (in response to tailpinch) did activate it. Again, this result was obtained on each of several tests with all 6 rats.

We conclude that vestibular stimulation, independent of active head movement, is not sufficient to activate atropine-resistant EEG.

After deafferentation of the labyrinth, the EEG did not change appreciably from normal before or after atropine (Table 1, Panels E, F, G, and H). A possible exception was the hippocampal EEG following atropine. The corre- lations are still substantial between the EEG and head movement following labyrinthectomy and drug administration (Table 1, Panel $\mathbf{H}$ ). However, there was a small diminution of the phi coefficient following atropine in each animal (Table 1, Panel D vs. Panel H) which, with a $t$ test for correlated observations, was statistically significant $[t(3)=3.57, p<.05]$. We conclude that the movementrelated activation of atropine-resistant hippocampal RSA, though clearly present, was diminished somewhat by labyrinthectomy.

In sum, labyrinthectomized rats injected with atropine sulfate did show essentially intact atropine-resistant EEG. Figure 2 displays a representative record contrasting the EEG before and after labyrinthectomy and before and after atropine. During head movements, activation of the atropine-resistant EEG occurred both before and after labyrinthectomy.

This was clearly demonstrated in rats made cataleptic and treated with atropine. Tailpinch-induced head movement was correlated with desynchronization of cortical activity (LVFA) and appearance of hippocampal RSA both before and after labyrinthine deafferentation ( $n=6$ out of 6 with several tests performed on each animal).

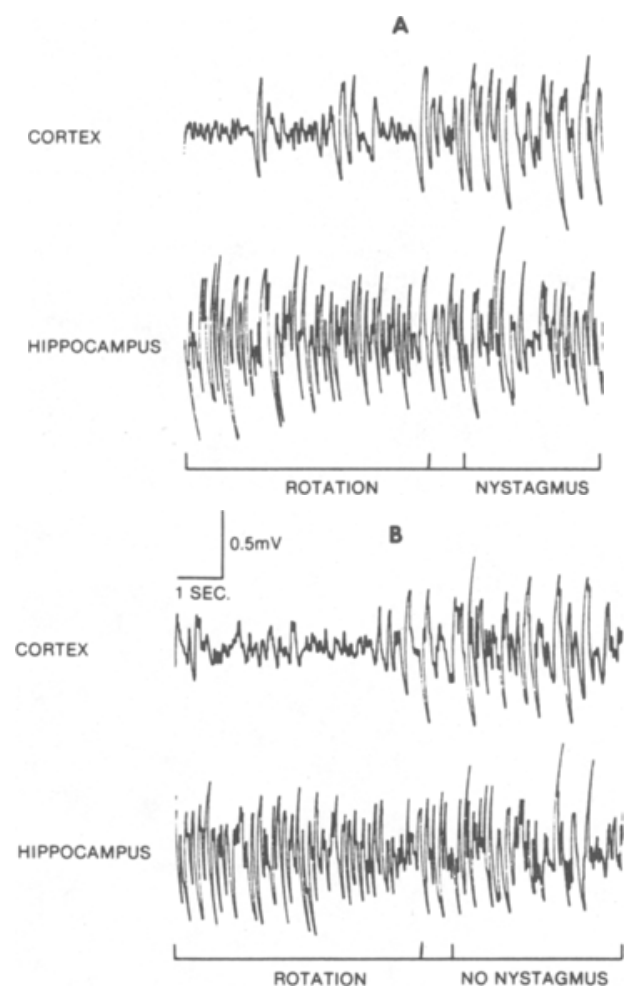

Figure 3. Cortical and hippocampal EEG during and following rotation on a turntable in a representative animal (DS-13). In both records, the animal was injected with both atropine and haloperidol. Voltage and time scales, shown in the center of the figure, were identical for both records. Record A: The vestibular intact animal, which showed cortical HVSA and hippocampal LIA during nystagmus, in the absence of head movements, following rotation. Record B: Postlabyrinthectomy, the animal again showed cortical HVSA and hippocampal LIA following rotation, although no nystagmus was observed. 
Figure 3 contrasts the EEG recorded postrotation in an atropinized rat before and after labyrinthectomy. Again, it is clear that labyrinthectomy failed to alter the occurrence of the atropine-resistant EEG. This test provided additional confirmation of the completeness of the labyrinthectomies, as postrotational ocular nystagmus was always absent in the labyrinthectomized animals.

The hippocampal EEG frequency was determined in 4 animals in which $2 \mathrm{sec}$ of LIA were followed by $2 \mathrm{sec}$ of RSA associated with the transition from immobility to movement (See Table 2).

A series of $t$ tests for correlated samples was performed on the tabled values to evaluate the effects of both atropine and labyrinthectomy on the hippocampal EEG frequency.

Before labyrinthectomy, a comparison of no drug versus drug (Table 2, Line 1 vs. Line 3 for each animal) showed that atropine decreased LIA frequency in each of the $2 \mathrm{sec}$ preceding movement $[t \mathrm{~s}(3)=3.23$ and 3.99 , respectively; $p s<.05$ ] but had no effect on the frequency of the RSA during either of the $2 \mathrm{sec}$ of movement $[t \mathrm{~s}(3)=.06$ and .37 , respectively; $p s>.05$ ]. This result confirms the report of Leung, Lopes da Silva, and Wadman (1982) of an atropine-sensitive component in the frequency spectra of hippocampal LIA.
After labyrinthectomy, a comparison of no drug versus drug (Table 2, Line 2 vs. Line 4 for each animal) showed the same pattern of results: LIA frequency was again reduced by atropine $[t \mathrm{~s}(3)=4.11$ and 3.00 , respectively; $p s \leq .05]$ but atropine had no effect on RSA frequency $[t \mathrm{~s}(3)=.68$ and 1.91 , respectively; $p \mathrm{~s}>.05]$.

Prior to drug administration, a comparison of preversus postlabyrinthectomy (Table 2 , Line 1 vs. Line 2 for each animal) showed that labyrinthectomy had no effect on LIA frequency at either recorded second [ts(3) = 1.03 and .04 , respectively; $p s>.05$ ]. However, labyrinthectomy reduced RSA frequency in the initial $[t(3)=$ $3.56, p<.05]$, but not in the latter $[t(3)=1.78$, $p>.05]$, recorded second.

Following drug administration, a comparison of preversus postlabyrinthectomy (Table 2 , Line 3 vs. Line 4 for each animal) showed essentially the same pattern of effect on hippocampal EEG frequency. LIA frequency was unaffected by labyrinthectomy at both recorded seconds $[t \mathrm{~s}(3)=.35$ and .18 , respectively; $p \mathrm{~s}>.05]$. However, labyrinthectomy significantly reduced RSA frequency during the second $[t(3)=26.42, p<.05]$, but not during the first $[t(3)=2.38, p>.05]$, recorded interval. These results suggest that, in the intact animal, vestibular signals may increase hippocampal RSA fre-

Table 2

Predominant Hippocampal Frequency During Transition from Immobility to Movement

\begin{tabular}{|c|c|c|c|c|c|c|c|}
\hline \multirow[b]{3}{*}{ Animal } & \multirow{3}{*}{$\begin{array}{l}\text { Haloperidol } \\
+ \text { Atropine }\end{array}$} & \multirow{3}{*}{$\begin{array}{c}\text { Vestibular } \\
\text { Deafferentation }\end{array}$} & \multicolumn{4}{|c|}{ Time (sec) } & \multirow[b]{3}{*}{$n$} \\
\hline & & & \multicolumn{2}{|c|}{ LIA } & \multicolumn{2}{|c|}{ RSA } & \\
\hline & & & 1 & 2 & 3 & 4 & \\
\hline \multicolumn{8}{|l|}{$\overline{\text { DS-7† }}$} \\
\hline 1 & - & - & $6.25 \pm 0.50$ & $6.13 \pm 0.29$ & $7.56 \pm 0.27$ & $7.50 \pm 0.39$ & 8 \\
\hline 2 & - & + & $6.17 \pm 0.48$ & $6.17 \pm 0.28$ & $6.92 \pm 0.24$ & $7.17 \pm 0.25$ & 6 \\
\hline 3 & + & - & $5.58 \pm 0.51$ & $5.75 \pm 0.53$ & $8.25 \pm 0.25$ & $8.25 \pm 0.25$ & 6 \\
\hline 4 & + & + & $5.67 \pm 0.38$ & $5.67 \pm 0.49$ & $7.75 \pm 0.21$ & $7.33 \pm 0.36$ & 6 \\
\hline \multicolumn{8}{|l|}{ DS-12 } \\
\hline 1 & - & - & $5.08 \pm 0.24$ & $5.42 \pm 0.44$ & $7.42 \pm 0.15$ & $7.17 \pm 0.17$ & 6 \\
\hline 2 & - & + & $6.67 \pm 0.54$ & $6.08 \pm 0.35$ & $7.25 \pm 0.33$ & $7.25 \pm 0.43$ & 6 \\
\hline 3 & + & - & $4.13 \pm 0.23$ & $4.06 \pm 0.35$ & $7.81 \pm 0.31$ & $7.63 \pm 0.18$ & 8 \\
\hline 4 & + & + & $4.36 \pm 0.34$ & $5.07 \pm 0.37$ & $7.36 \pm 0.24$ & $6.71 \pm 0.21$ & 7 \\
\hline \multicolumn{8}{|l|}{ DS-13 } \\
\hline 1 & - & - & $6.67 \pm 0.49$ & $7.08 \pm 0.30$ & $7.75 \pm 0.25$ & $7.92 \pm 0.24$ & 6 \\
\hline 2 & - & + & $6.43 \pm 0.25$ & $6.43 \pm 0.32$ & $7.50 \pm 0.27$ & $7.79 \pm 0.18$ & 7 \\
\hline 3 & + & - & $5.32 \pm 0.30$ & $5.71 \pm 0.30$ & $7.61 \pm 0.32$ & $8.00 \pm 0.19$ & 14 \\
\hline 4 & + & + & $4.58 \pm 0.44$ & $5.50 \pm 0.45$ & $5.83 \pm 0.11$ & $7.17 \pm 0.28$ & 6 \\
\hline \multicolumn{8}{|l|}{ DS-17 } \\
\hline 1 & - & - & $6.07 \pm 0.49$ & $6.43 \pm 0.55$ & $7.86 \pm 0.39$ & $7.79 \pm 0.41$ & 7 \\
\hline 2 & - & + & $6.50 \pm 0.39$ & $6.42 \pm 0.44$ & $7.33 \pm 0.21$ & $7.33 \pm 0.25$ & 6 \\
\hline 3 & + & - & $3.44 \pm 0.26$ & $4.56 \pm 0.29$ & $7.00 \pm 0.35$ & $7.00 \pm 0.40$ & 8 \\
\hline 4 & + & + & $4.33 \pm 0.40$ & $4.08 \pm 0.27$ & $6.58 \pm 0.37$ & $6.00 \pm 0.32$ & 6 \\
\hline \multicolumn{8}{|c|}{ Contrasts } \\
\hline & \multirow{3}{*}{\multicolumn{2}{|c|}{$\begin{array}{l}\text { Lines } 1 \text { vs. Lines } 3 \\
\text { Lines } 2 \text { vs. Lines } 4 \\
\text { Lines } 1 \text { vs. Lines } 2 \\
\text { Lines } 3 \text { vs. Lines } 4\end{array}$}} & $*$ & $*$ & & & \\
\hline & & & $*$ & $*$ & & & \\
\hline & & & & & $*$ & * & \\
\hline
\end{tabular}

Note-Entries are frequency means \pm 1 standard error (counted by zero-crossings) of hippocampal EEG waves during successive 4-sec episodes of which the first $2 \mathrm{sec}$ were LIA and the next $2 \mathrm{sec}$ were RSA, associated with transition from immobility to movement. The $n$ column is the number of episodes sampled. ${ }^{*} p \leq .05$ in a $t$ test for correlated samples between conditions. See text for details. †This animal received atropine sulfate only. 
quency during movement with or without the influence of atropine.

Histology was not performed to determine the effectiveness of either the surgical or the chemical labyrinthectomy procedures in the present study. However, both of these procedures, as carried out in our laboratory, have been shown to result in vestibular nerve degeneration in the brain stem (Chen, Pellis, Sirkin, Potegal, \& Teitelbaum, 1986). This evidence bolsters the behavioral assessments detailed above, which served as our criterion of successful labyrinthectomies.

\section{GENERAL DISCUSSION}

Previous reports (e.g., Schallert et al., 1980; Vanderwolf, 1975), as well as the present investigation, show that the shift from the atropine-sensitive EEG recorded during immobility to the atropine-resistant EEG during movements other than grooming, chewing, tooth chattering, and licking is dramatic. The present report, in which the relationship was quantified in several animals, verifies this effect and shows as well that it is highly correlated.

In addition, the results of the present investigation clearly demonstrate that movement-related atropine-resistant EEG is present in the absence of vestibular input. However, closer analysis shows a reduction in the frequency of hippocampal RSA due to removal of vestibular signals both with and without atropine influence. The same analysis shows that an atropine-sensitive component present in hippocampal LIA during immobility is not affected by deafferentation of the labyrinth. Thus, vestibular modulation of the hippocampal EEG appears restricted to movement.

We also confirmed earlier demonstrations (Vanderwolf, 1975; Whishaw, 1976) that vestibular stimulation by passive movement is not sufficient to activate atropineresistant EEG. In the Vanderwolf and the Whishaw studies, as well as in the present study, vestibular stimulation was implied from the passive head movement. However, we further observed postrotation vestibular activity independent of movement, as reflected by ocular nystagmus, in vestibular-intact, haloperidol- and atropine-treated rats, and we observed that atropine-resistant EEG was absent during the ocular nystagmus episode.

The fact that removal of vestibular stimuli affected only movement-related hippocampal RSA while atropinesensitive LIA remained unchanged, and the fact that passive movement failed to induce atropine-resistant EEG, suggests that reafferent vestibular signals from active movement modulate the atropine-resistant EEG.

Previous studies are cited in the literature as evidence that the atropine-resistant EEG is independent of vestibular activity, but in none of these studies is there a convincing demonstration of complete labyrinthine blockade. For example, Fredrickson et al. (1982) reported that atropineresistant EEG was present in genetically mutant mice lacking the gravity-receptor organ but possessing semicircular canals of the vestibular apparatus. Furthermore, in mammalian REM sleep, there is a characteristic neckmuscle atonia during which the head is resting, and yet atropine-resistant EEG is present some of the time. This has been taken to indicate the lack of a role for vestibular signals in atropine-resistant EEG (Robinson et al., 1977). However, Robinson et al. observed atropine-resistant EEG during REM sleep of vestibular-intact rats associated exclusively with "phasic events" such as head (vestibular stimulation?) and/or limb twitches, vibrissae movements, and so forth. This finding, and evidence that the medial vestibular nucleus is important for phasic events of REM sleep (Pompeiano \& Morrison, 1965), would appear to strengthen, rather than weaken, the impression that vestibular signals are important for atropineresistant EEG.

In other studies, locomotion without head movement was used to eliminate vestibular stimulation. For example, in an unpublished study cited by Vanderwolf (1979), the head of a trifluoperazine-treated and atropinized rat was fixed in a stereotaxic frame. Stepping movements were elicited by rotating a wood block on which the rat stood. Atropine-resistant EEG was still present.

In support of these reports of atropine-resistant EEG under conditions designed to limit vestibular activity, our finding of atropine-resistant EEG in freely moving labyrinthectomized rats provides clear evidence that vestibular signals are not necessary for activation of atropineresistant EEG. After submission of the present work for publication, we became aware (C. H. Vanderwolf, personal communication, August 24,1988 ) of the unpublished work of Harvey (1980), in which rats that received either vestibular lesions or sections of Cranial Nerves 7 and 8 both showed atropine-resistant EEG. Our findings corroborate this result and show furthermore that vestibular signals modulate hippocampal RSA frequency. This frequency modulation may be related to a report by Whishaw (1982) in which hippocampal RSA frequency acceleration was noted during contact-righting of vestibular-intact rabbits. In that study, the atropine resistance of the frequency acceleration was not determined.

In the present investigation, we found no effect of labyrinthectomy on the atropine-sensitive component of hippocampal LIA in immobile rats, but we observed a decrease in the frequency of the hippocampal RSA component associated with active movement both with and without atropine. This leads us to conclude that the effect of labyrinthectomy on hippocampal RSA was specific to movement and that it probably reflects reafferent vestibular input from active, self-initiated movement.

\section{REFERENCES}

Chen, Y.-C., Pellas, S. M., Sirkin, D. W., Potegal, M., \& TeitelBAUM, P. (1986). Bandage backfall: Labyrinthine and non-labyrinthine components. Physiology \& Behavior, 37, 805-814. 
Cummings, H. (1924). The vestibular labyrinth of the albino rat: Form and dimensions and the orientation of the semicircular canals, cristae and maculae. Journal of Comparative Neurology, 38, 399-445.

DeRyck, M., \& Teitelbaum, P. (1978). Neocortical and hippocampal EEG in normal and lateral hypothalamic rats. Physiology \& Behavior, 20, 403-409.

DeRyck, M., \& Teitelbaum, P. (1979). Electrophysiological cortelates of normal and haloperidol-induced immobility in rats. Society for Neuroscience Abstracts, 5, 583.

Fredrickson, C. J., Fredrickson, M. H., Lewis, C., Howell, G. A., SmyLie, C., Wright, C. G., \& HubBard, D. G. (1982). Hippocampal EEG in normal mice and in mice with congenital vestibular deficits. Behavioral \& Neural Biology, 34, 121-131.

GACEK, R. R. (1975). The innervation of the vestibular labyrinth. In R. F. Naunton (Ed.), The vestibular system (pp. 21-30). New York: Academic Press.

Greene, E. C. (1963). Anatomy of the rat. New York: Hafner.

HarveY, G. C. (1980). The effects of vestibular lesions on hippocampal rhythmical slow activity during active sleep and waking behavior in rats. Unpublished master's thesis, University of Western Ontario, London, Ontario.

Horn, K. M., DeWItT, J. R., \& Nielson, H. C. (1981). Behavioral assessment of sodium arsanilate induced vestibular dysfunction in rats. Physiological Psychology, 9, 371-378.

JONGKEES, L. B. W. (1975). On the physiology and the examination of the vestibular labyrinths. In R. F. Naunton (Ed.), The vestibular system (pp. 227-247). New York: Academic Press.

Leung, L.-W. S., Lopes da Silva, F. H., \& Wadman, W. J. (1982). Spectral characteristics of hippocampal EEG in the freely moving rat. Electroencephalography and Clinical Neurophysiology, 54, 203-219.
Pompeiano, O., \& Morrison, A. R. (1965). Vestibular influences during sleep: 1. Abolition of the rapid eye movements of desynchronized sleep following vestibular lesions. Archives Italiennes de Biologie, 103, 569-595.

Robinson, T. E., Kramis, R. C., \&anderwolf, C. H. (1977). Two types of cerebral activation during active sleep: Relation to behavior. Brain Research, 124, 54i-549.

Schallert, T., DeRyck, M., Teitelauum, P. (1980). Atropinestereotypy as a behavioral trap: A movement subsystem and electroencephalographic analysis. Joumal of Comparative \& Physiological Psychology, 94, 1-23.

VANDERWOLF, C. H. (1975). Neocortical and hippocampal activation in relation to behavior: Effects of atropine, eserine, phenothiazines and amphetamine. Journal of Comparative \& Physiological Psychology, 88, 300-323.

VANDERWOLF, C. H. (1979). Is hippocampal rhythmical slow activity specifically related to movement through space? Behavioral \& Brain Sciences, 2, 518-519.

Whishaw, I. Q. (1976). The effects of alcohol and atropine on EEG and behavior in the rabbit. Psychopharmacologia, 48, 83-90.

WhishaW, I. Q. (1982). A simple behavioral paradigm for the study of Type I hippocampal rhythmical slow activity (RSA) frequency shifts. Physiology \& Behavior, 29, 751-753.

Winson, J. (1976). Hippocampal theta rhythm: 1. Depth profiles in the curarized rat. Brain Research, 103, 71-80.

(Manuscript received July 20, 1987; revision accepted for publication March $15,1989$.

\title{
Announcement
}

\author{
International Congress of Psychology \\ Brussels, Belgium \\ July 19-24, 1992
}

The next International Congress of Psychology will be held in Brussels, July 19-24, 1992, under the auspices of the International Union of Psychological Science (IUPsyS).

Congress brochures may be obtained from Brussels International Conference Centre, Place des Expositions, Place de Belgique, B-1020 Brussels, Belgium (FAX 3224788023 ).

Proposals for the Scientific Program, including symposia, may be sent to the U.S. member of IUPsyS, the National Academy of Science. They should be addressed to Pamela Ebert Flattau, USNC/IUPsyS, National Research Council, GH 186, 2101 Constitution Avenue, N.W., Washington, D.C. 20418. 